\title{
Activity-Dependent Gene Regulation in Conditionally-Immortalized Muscle Precursor Cell Lines
}

\author{
Peter C.D. Macpherson, ${ }^{1}{ }^{*}$ Steven T. Suhr, ${ }^{1}$ and Daniel Goldman ${ }^{1,2}$ \\ ${ }^{1}$ Mental Health Research Institute, University of Michigan, Ann Arbor, 205 Zina Pitcher Pl., Ann Arbor, \\ Michigan 48109-0720 \\ ${ }^{2}$ Department of Biological Chemistry, University of Michigan, Ann Arbor, 205 Zina Pitcher Pl., Ann Arbor, \\ Michigan 48109-0720
}

\begin{abstract}
Skeletal muscle contractile activity has been implicated in many aspects of muscle cell differentiation and maturation. Much of the research in this area has depended upon costly and labor-intensive cultures of isolated primary muscle cells because widely available immortalized muscle cell lines often do not display a high level of either spontaneous or stimulated contractile activity. We sought to develop conditionally-immortalized skeletal muscle cell lines that would provide a source of myofibers that exhibit robust spontaneous contractile activity similar to primary muscle cultures. Using a tetracycline-regulated retroviral vector expressing a temperature-sensitive T-antigen to infect primary myoblasts, we isolated individual clonal muscle precursor cell lines that have characteristics of activated satellite cells during growth and rapidly differentiate into mature myotubes with spontaneous contractile activity after culture in nontransformation-permissive conditions. Comparison of these cell lines (known as rat myoblast-like tetracycline (RMT) cell lines) to primary cell cultures revealed that they share a wide variety of morphological, physiological, and biochemical characteristics. Most importantly, the time-course and extent of activity-dependent gene regulation observed in primary cell culture for all genes tested, including subunits of the nicotinic acetylcholine receptor (nAChR), muscle specific kinase (MuSK), and myogenin, is reproduced in RMT lines. These immortalized cell lines are a useful alternative to primary cultures for studying muscle differentiation and molecular and physiological aspects of electrical activity in muscle fibers. J. Cell. Biochem. 91: 821-839, 2004. (c) 2004 Wiley-Liss, Inc.
\end{abstract}

Key words: spontaneous contractions; conditional immortalization; myogenic transcription factors; T-antigen; NIT; satellite cell

Activity-dependent gene regulation has been implicated in many aspects of skeletal muscle differentiation and maturation. During myoblast differentiation, the family of myogenic transcription factors (MTF) MyoD, Myf-5, MRF4, and myogenin is differentially expressed, but as myotubes mature, become innervated and functionally active, expression levels

Peter C.D. Macpherson and Steven T. Suhr contributed equally to this work.

Grant sponsor: NINDS; Grant number: 5R01WS025153-16; Grant sponsor: Hereditary Disease Foundation (to S.T.S.).

${ }^{*}$ Correspondence to: Peter C.D. Macpherson, Mental Health Research Institute, University of Michigan, 205 Zina Pitcher Pl., Ann Arbor, MI 48109-0720.

E-mail: petercdm@umich.edu

Received 17 September 2003; Accepted 22 October 2003

DOI 10.1002/jcb.10784

(c) 2004 Wiley-Liss, Inc. are suppressed [Duclert et al., 1991; Buonanno et al., 1992; Adams et al., 1995; Buckingham et al., 2003]. Similarly, nicotinic acetylcholine receptor ( $\mathrm{nAChR}$ ) expression is high during the initial stages of myotube development, but is suppressed once innervated fibers become functionally active [Goldman et al., 1988; Witzemann et al., 1991]. In contrast, expression of myosin isoforms change on multiple occasions during muscle fiber maturation [Whalen et al., 1981], but ultimately are controlled by the degree of muscle activity via nerve stimulation [Buller et al., 1969; Pette and Vrbova, 1992]. These components of skeletal muscle as well as metabolic enzymes and sarcoplasmic reticulum constituents show clear evidence of the importance of contractile activity in regulating muscle specific gene expression.

The vast majority of activity-dependent gene regulation research has been performed on isolated primary muscle cells in vitro or whole 
muscles in vivo. Although these model systems remain the gold standard by which experimental data is and should be evaluated, they present significant technical and scientific drawbacks. Isolation of primary muscle cells is time consuming, costly, and often unpredictable with respect to yield and contamination with nonmuscle cells. Similarly, in vivo muscle research typically requires a large number of animals which can be costly, and time consuming and introduces an additional level of expertise with respect to surgical technique. Moreover, in both cases, cell heterogeneity often contributes to difficulty in the interpretation of results.

An alternative to isolation of primary muscle cells for in vitro experimentation is the use of an immortalized muscle cell line of which there are a number [Yaffe, 1968; Kimes and Brandt, 1976; Linkhart et al., 1980; Blau et al., 1983; Mulle et al., 1988]. Although these cell lines have been extremely useful in gaining insight into cell cycle regulation and myotube differentiation, in our hands, they have not proven optimal for the study of activity-dependent gene expression because they do not display a high level of contractile activity. To further our studies of muscle development, maintenance, and in particular, activity, we sought to develop skeletal muscle cell lines from rat primary muscle cell cultures. Of particular interest to us were cell lines that demonstrated rapid cell proliferation followed by differentiation into mature, active, myofibers that reproduced the features of activity-dependent gene regulation observed in primary cell cultures and whole muscle in vivo.

We elected to use the SV40 large T-antigen (Tag) [Aaronson and Todaro, 1968; Henderson and Livingston, 1974] as a transforming agent. Tag has proven very effective for generating immortalized transformed cell lines from a variety of tissues and species including mesoderm-derived tissues such as bone, cartilage, and muscle [Iujvidin et al., 1990; Yang et al., 1992; Simon et al., 1996; Hicok et al., 1998; Robbins et al., 2000]. Temperature-sensitive Tag variants have the added benefit of permitting reversal of transformation through inactivation of the Tag protein at a non-permissive temperature of $37-39^{\circ} \mathrm{C}$ [Tenen et al., 1977; Brown et al., 1986; Jat and Sharp, 1989; Iujvidin et al., 1990]. An additional level of control over the immortalized state was introduced through the use of a retroviral vector known as NIT-Tag to infect the primary rat myoblasts. In addition to permitting a reduction of Tag-mediated transformation by thermodenaturation of the Tag protein, the NIT-Tag vector also allows blocking of Tag protein expression through the introduction of tetracycline-analogs into the culture medium and inactivating a "tet-off" tetracycline-transactivator (TTA) protein [Gossen and Bujard, 1992; Hoshimaru et al., 1996] expressed from the NIT vector. The combination of both inhibitors was predicted to very tightly and rapidly regulate the transformation status of infected cells.

Conditionally-immortalized myogenic cell lines expressing temperature-sensitive T-antigen have been produced by a number of laboratories and from a number of species using both Tantigen-expressing transgenic mice and viral vectors [Iujvidin et al., 1990; Yang et al., 1992; Simon et al., 1996]. These reports are variable in their depth of characterization of the differentiation status of generated lines (in large part because many of the markers of myogenic differentiation have only been characterized within the last few years) and either make no mention of contractile activity, or present no data regarding the molecular, biochemical, or physiological changes accompanying it. Furthermore, since a major goal of this study is to determine to what degree these conditionally-immortalized cell lines can reproduce activity-dependent gene regulation observed in primary cell cultures, we felt that in order to directly correlate with earlier work from the laboratory, the lines should derive directly from the primary cell cultures that we routinely generate.

We have generated cell lines using the NITTag retrovirus that are readily perpetuated in culture and have been subcloned and characterized as individual clonal lines. We have used molecular markers to characterize these lines during active growth, contact inhibition, and after differentiation in a combination of culture conditions. Many of the lines differentiate into myofibers with features of mature muscle including contractile activity. We have compared these cells to primary cell cultures and despite the obvious differences in purity and uniformity of the starting population, most morphological, molecular, developmental, and contractile characteristics examined are highly similar. The data presented indicate that these immortalized cell lines will be a useful alternative to primary cell cultures for laboratories 
studying muscle development and differentiation and laboratories studying questions related to contractile activity and electrical responses of muscle fibers.

\section{MATERIALS AND METHODS}

\section{Viral Vectors, Infection, and Clonal Selection}

The NIT-Tag vector was produced by insertion of a Bam HI fragment encoding a full-length temperature-sensitive SV40 Tag into the tetracycline-regulated MMLV-based, replicationdefective retroviral vector NIT. The NIT-Tag retrovirus was packaged in HEK293T cells using triple plasmid co-transfection as described for other MMLV-based retroviruses [Suhr et al., 2001]. Rat primary myoblasts, isolated as described previously [Goldman et al., 1991], were plated on $35 \mathrm{~mm}$ collagen-coated culture dishes at a density of approximately $1 \times 10^{6}$ cells/plate and allowed to grow at $37^{\circ} \mathrm{C} /$ $8 \% \mathrm{CO}_{2}$ in growth medium (DMEM supplemented with $10 \%$ fetal bovine serum (FBS) and $10 \%$ horse serum). After growth for $18 \mathrm{~h}$, plates of adherent cells were infected by the addition of NIT-Tag virus conditioned medium at an estimated MOI of 0.1 and transferred to $32^{\circ} \mathrm{C}$. After an additional $24 \mathrm{~h}$ of growth, the infected cells were passaged to $150 \mathrm{~mm}$ culture plates at a density of $1 \times 10^{5}$ cells/plate and placed under selection in G418 $(500 \mu \mathrm{g} / \mathrm{ml})$ for 10 days. After selection was complete, 91 G418-resistant colonies that were well separated from neighboring colonies were picked and transferred to 24-well plates for additional growth. Of these colonies, 42 displayed robust growth at low-density with continued selection and were passaged in duplicate to a second set of 24-well plates for further analysis. On the duplicate plate, cells were grown to 50-100\% confluency and switched to differentiation conditions to determine whether they were capable of differentiating into myotubes. Preliminary experiments indicated that, like primary cell cultures and other myoblast cell lines such as $\mathrm{C} 2 \mathrm{C} 12$, serum concentration could significantly affect the differentiation rate of the NIT-Tag-immortalized cells lines (data not shown). FBS concentrations ranging from 5 to $15 \%$ were found to readily support their growth, while FBS concentrations $<1 \%$, or concentrations of heatinactivated horse serum (HIHS) of $5 \%$ or less coupled with the temperature shift and doxycycline (dox) (a potent tetracycline analog) addi- tion resulted in dramatic slowing or complete cessation of cell division and subsequent myofiber formation (data not shown). Unless otherwise specified, both cell lines and primary cells were differentiated at $37^{\circ} \mathrm{C}$ in differentiation medium (DM) containing DMEM $/ 5 \%$ HIHS. DM for NIT-Tag-immortalized cell lines was further supplemented with $1 \mu \mathrm{g} / \mathrm{ml}$ dox. After 10 days of differentiation, most of the colonies displayed observable differences in cell morphology and five displayed numerous myotubes. These five lines numbered $22,46,59,62$, and 63 , as well as five fibroblast-like lines, 8, 34, 55, 64, and 70 were expanded, tested for the presence of helper virus (found to be negative), and cryogenically preserved in multiple aliquots for further analysis. Each of the myotube-forming lines was subject to further clonal selection by limiting-dilution plating to 96 -well plates. These individual clones were then expanded and analyzed individually to compare growth rate, morphology, differentiation, and other characteristics. DNA blot analysis using standard methods revealed an identical banding pattern of the integrated NIT-Tag provirus within individual clones isolated by limiting dilution, but a different pattern comparing between parental lines, suggesting that the parental lines tested arose from independent infections. A single integration was observed in all lines examined except for clones from line 46 that displayed two bands suggesting two proviral integrations (data not shown). The first clonal line of each group was expanded and used for further characterization. These are myoblast-like lines 221, 461, 5951, 6211, and 631, and for purposes of comparison, the fibroblastlike line 8. Myoblast-like myotube-forming lines are heretofore designated RMT cells for rat myoblast-like tetracycline-responsive cells and fibroblast-like lines are designated RFT cells for rat fibroblast-like tetracycline-responsive cells.

\section{Electrical Stimulation}

Rat primary myoblasts were isolated and plated as described above. Between 48 and $96 \mathrm{~h}$ post-plating primary cell cultures became confluent and the media was changed to DM to induce myotube formation. At this time, cells were treated with $3 \mu \mathrm{g} / \mathrm{ml}$ cytosine arabinoside for $48 \mathrm{~h}$ to inhibit fibroblast proliferation. RMT cell lines were plated at a density of approximately $10^{5}$ /plate in growth medium and allowed to proliferate at $32^{\circ} \mathrm{C}$ until confluent. Upon 
reaching confluence, the media was changed to DM with dox and the plates were shifted to $37^{\circ} \mathrm{C}$. Discernible differentiation and myotube formation of RMTs typically commenced 3 days after switching to DM. Primary and RMT myotubes were continuously treated with $1 \mu \mathrm{g} / \mathrm{ml}$ tetrodotoxin (TTX) (Oretek, Inc., Fremont, CA) from the onset of myotube formation until time of electrical stimulation (7-10 days). Prior to experiments in which myotubes were electrically stimulated, cultures were rinsed three times with TTX free media, and then returned to the incubator briefly before checking for spontaneous contractile activity. Myotubes were then electrically stimulated to contract for up to $48 \mathrm{~h}$ using conditions described previously [Macpherson et al., 2002]. Data are presented for myotubes that were electrically stimulated for $6 \mathrm{~h}$.

\section{Transfections}

To obtain agrin condition media RMT461 myotubes were co-transfected with plasmids containing expression vectors for either soluble or membrane bound forms of agrin [Ferns et al., 1993] and green fluorescent protein (GFP). pCMV-cAg4,8 and pCMV-Ag12,4,8 (generously provided by Dr. M. Ferns) harbor soluble and membrane bound forms of the agrin gene, respectively, which are down stream of the cytomegalovirus promoter. pCS2EGFP, containing the cytomegalovirus promoter driving GFP expression, was used to identify transfected cells and determine transfection efficiency. RMT461 myotubes were co-transfected with $0.5 \mu \mathrm{g}$ of pCS2EGFP and either $1.5 \mu \mathrm{g}$ of pCMV-Ag12,4,8 or pCMV-cAg4,8. Total DNA was adjusted to $3 \mu \mathrm{g} /$ plate using pBSK (Stratagene, La Jolla, CA). Transfections were performed by calcium phosphate precipitation as previously described [Chahine et al., 1992].

\section{RNA Isolation and RNase Protection Assay}

Total RNA was isolated by homogenizing cell cultures in Trizol (Gibco BRL, Grand Island, NY) followed by the single step purification method as described by the manufacture's protocol. Antisense probes used to detect myogenin and the nAChR $\alpha-, \beta-, \delta$-, $\gamma$-, and $\varepsilon$-subunit RNAs were the same as those described by [Chahine et al., 1993]. The muscle specific kinase (MuSK) probe is a HindIII/ApaI subclone of the rat MuSK cDNA (provided by Dr. S.J. Burden).
This probe spans nucleotides 1426-1899 of the published rat cDNA [Valenzuela et al., 1995]. The p21 probe is a clone of the mouse cDNA (provided by Dr. K. Huppi) that when linearized with SmaI protects approximately 250 nucleotides of rat p $21 \mathrm{mRNA}$. The retinoblastoma $(\mathrm{Rb})$ probe is a Kpn1/Pst1 subclone of the mouse Rb cDNA (provided by Dr. E. Wang) that when linearized with Nde1 protects approximately 340 nucleotides of rat $\mathrm{Rb}$ mRNA. RNase protection assays were carried out as previously described [Adams and Goldman, 1998]. The probe for glyceraldehyde-3-phosphate dehydrogenase (GAPDH) was obtained from Ambion (Austin, TX). GAPDH probes were included in each experiment and served to normalize for differences in the amount of RNA in each of the samples based on the observation that electrical stimulation of skeletal muscle does not regulate GAPDH gene activity [Huang et al., 1992]. The RNA for GAPDH was not regulated by any of the conditions employed in this report. RNase resistant hybrids were analyzed on $6 \%$ polyacrylamide, $8 \mathrm{M}$ urea gels. After electrophoresis, gels were dried and exposed to the X-ray film. Probe signals were quantified by scanning densitometry and values were normalized to the RNA signal obtained for GAPDH. The specificity of the protected bands was confirmed by hybridizing probes to tRNA, which resulted in no protected fragments on the gel. Probe integrity was monitored for each experiment by running an aliquot of non-hybridized probe on each gel.

\section{Western Blots}

Cell lysates from cultured myotubes were prepared by scraping cells from the dishes in RIPA buffer (50 mM Tris-HCl, $\mathrm{pH} 8.0,1 \%$ NP-40, 0.5\% deoxycholate, $0.1 \%$ SDS, $150 \mathrm{mM}$ $\mathrm{NaCl}, 1 \mathrm{mM}$ EDTA) containing a protease inhibitor cocktail (P8340 Sigma, St. Louis, MO) at a dilution of 1:100. Cells were sheared by passing through a 26.5 gauge needle and centrifuged briefly to remove cellular debris. Protein concentrations were determined using the Bio-Rad DC protein assay (Hercules, CA). Protein samples were subjected to SDS-PAGE (10\%) and transferred electrophoretically to Immobilon-P membranes (Millipore, Bedford, MA). After electro-transfer the proteins remaining in the gels were stained with Coomassie brilliant blue and used as an additional control for equilibration of protein loading. After trans- 
fer, Immobilon-P membranes were blocked in Blotto buffer containing 5\% dry milk in PBST (phosphate-buffered saline/0.2\% Tween-20) and then incubated overnight at $4{ }^{\circ} \mathrm{C}$ with mouse myogenin monoclonal antibody (mAb) supernatant 1:50 (clone F5D, obtained from the Developmental Studies Hybridoma Bank) or at room temperature for $1-2 \mathrm{~h}$ with rabbit polyclonal antibodies MyoD, Myf-5, or MRF4 1:1,000 (sc-760, sc-302, sc-784, respectively, Santa Cruz Biotechnologies, Santa Cruz, CA). Immunodetection was done using peroxidaseconjugated secondary antibodies, goat antimouse or goat anti-rabbit, 1:1,000 (Jackson ImmunoResearch Lab., West Grove, PA) with subsequent chemiluminescent detection (ECL, Amersham Pharmacia Biotech, Piscataway, $\mathrm{NJ})$.

\section{Immunohistochemistry}

For all comparative immunocytochemical studies, cells within an experiment were grown, harvested, fixed, and processed identically and in parallel to provide favorable cross-comparison. For immunohistochemical analysis, tissue culture plates or multi-well plates were rinsed with PBS and fixed with $2 \%$ paraformaldehyde for approximately $30 \mathrm{~min}$. After fixation, plates were rinsed $5 \times$ in PBS and then blocked with $10 \%$ serum containing $0.3 \%$ Triton X-100 for $1 \mathrm{~h}$ at room temperature. Incubation of monoclonal or polyclonal antibodies was at $4^{\circ} \mathrm{C}$ overnight. After removing primary antibodies the plates were rinsed $3 \times$ in PBS for 5 min and then incubated with the appropriate secondary antibody. To visualize nAChR clusters, plates were incubated with Texas Red conjugated $\alpha$-bungarotoxin ( $\alpha$-BTX) (1:1,000 dilution) (B-7489, Molecular Probes, Eugene, OR) for $1 \mathrm{~h}$ at room temperature. Antibody and other reagent sources were as follows: monoclonal anti-myogenin (1:50 dilution), anti-myosin (1:250 dilution), and anti-Pax7 (1:200) (clones F5D, MF20, and PAX7, respectively) were obtained from the Developmental Studies Hybridoma Bank; rabbit polyclonal antibody against MyoD (1:200 dilution), Myf-5 (1:250 dilution), or MFR4 (1:250 dilution) obtained from Santa Cruz Biotechnologies, Inc.; goat anti-mouse, goat anti-rabbit, donkey anti-mouse used at 1:250 dilution, donkey anti-rabbit used at 1:250 dilution (Jackson ImmunoResearch Lab.); Tag antibody used at 1:500 dilution (MAB986 Chemicon, Temecula, CA), DAPI stain (Sigma).

\section{Statistics}

Mean \pm SD were determined for samples from primary and RMT cultures. Differences in mean values of $R b, p 21$, myogenin MuSK and nAChR mRNA were compared within groups (e.g., primary TTX treated vs. primary stimulated) and significant differences were determined by $t$-tests analysis. The level of significance was set a priori at $P<0.05$.

\section{RESULTS}

Primary myoblasts were immortalized by the NIT-Tag retrovirus that combines advantages of temperature-sensitive Tag with tetracycline regulation into a single vector that provides tight conditional control over cell immortalization. NIT-Tag shown schematically in Figure 1A, encodes two expression cassettes. The first cassette is expressed from the $5^{\prime}$ viral LTR and encodes a $G 418$ (neomycin) resistance gene, an internal ribosomal entry site (IRES), and the TTA protein. TTA transactivates expression of the second expression cassette through a TTA-responsive promoter (To) to produce the Tag gene product. A shift to the nonpermissive temperature $\left(37^{\circ} \mathrm{C}\right)$ destabilizes the Tag protein conformation resulting in a reduction in transforming function (Fig. 1B). In addition to temperature shift, high-level expression of Tag via TTA transactivation can be blocked by the addition of tetracycline analogs such as dox, further inhibiting the Tag-mediated transformation (Fig. 1C). As described in "Materials and Methods," 42 neomycin-resistant NIT-Tag infected cell lines were grown in parallel and tested in an initial screen for their capacity to differentiate into multinucleate myofibers. Several lines indicated a high degree of myofiber formation, and the results for one parental line, RMT46 are shown in Figure 1D. RMT46 maintained at $32^{\circ} \mathrm{C}$ in growth medium showed a healthy, dense monolayer of mononuclear cells after 1 week of continuous proliferation (growing) whereas an identically plated culture that was shifted to DM supplemented with $1 \mu \mathrm{g} / \mathrm{ml}$ dox for the same duration at $37^{\circ} \mathrm{C}$ displayed numerous multinucleate muscle fibers and virtually no mononuclear cells (differentiated).

We then compared the individual and combined effects of temperature and dox treatment on the growth and differentiation of NIT-TAg infected cell lines cultured for 1 week under the following four conditions: $32^{\circ} \mathrm{C}, 37^{\circ} \mathrm{C}$, 

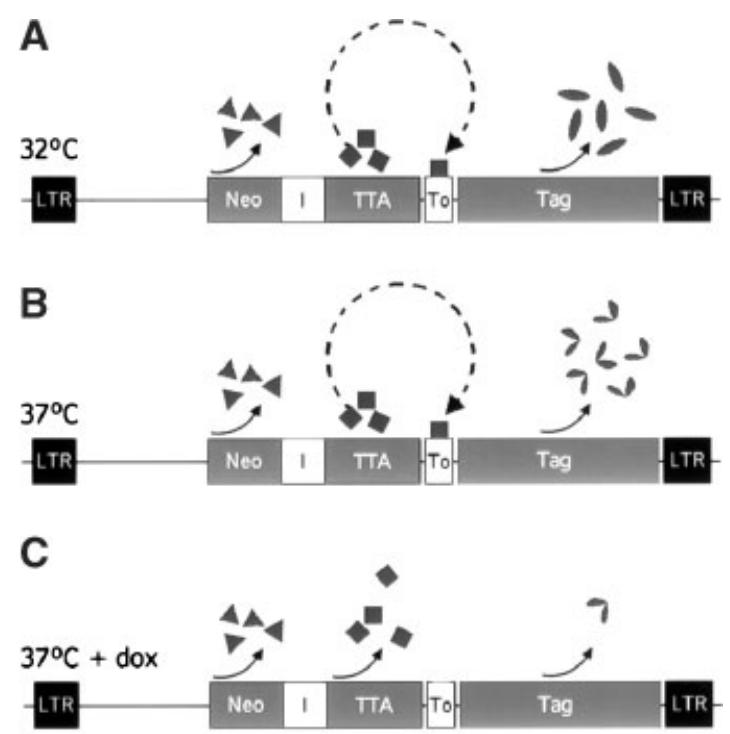

D
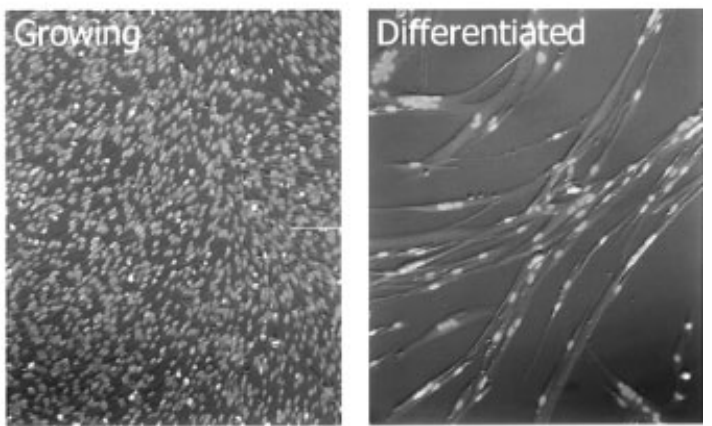

Fig. 1. The NIT-Tag virus and conditional differentiation of infected cells. A-C: Schematic of the NIT-Tag provirus and predicted function under different conditions with abbreviations as follows: LTR, viral LTR (promoter); Neo, neomycin (G418) resistance gene; I, internal ribosomal entry site (IRES) element; TTA, tetracycline-transactivator; To, TTA-responsive promoter; Tag, temperature-sensitive SV40 T-antigen. A: $32^{\circ} \mathrm{C}$, allows full expression of active Tag; (B) $37^{\circ} \mathrm{C}$, inhibition of Tag by heatinactivation (cleaved ovals); (C) $37^{\circ} \mathrm{C}+$ dox, dual inhibition of Tag function by heat inactivation coupled with dox-mediated block of expression. D: $200 \times$ Brightfield image overlaid with an image of DAPI-staining (to highlight nuclei) of line rat myoblastlike tetracycline (RMT) 46 at $32^{\circ} \mathrm{C}$ (growth), and at $37^{\circ} \mathrm{C}$ with dox (differentiation).

$32^{\circ} \mathrm{C}+$ dox, and $37^{\circ} \mathrm{C}+$ dox. For this next level of analysis, clonal lines isolated by limiting dilution of each of the parental cell lines (described in "Materials and Methods") were used. Differentiation was grossly determined by the formation of multi-nucleated myotubes in the culture plate. All RMT cell lines followed a similar trend toward differentiation and the results are shown for lines RMT461, RMT631, and RFT8 in Figure 2. The RFT8 line was included to show that morphological and biochemical changes characteristic of RMT differentiation are not the result of NIT infection, dox treatment, or even simple changes in the proliferative status of the cell, but are instead likely to arise from the fundamental character or "lineage" of the original infected cell.

As shown in Figure 2, the most permissive growth conditions $\left(32^{\circ} \mathrm{C}\right)$ resulted in continuous cell proliferation as suggested by multiple mitotic profiles and exclusively mono-nucleated cells (Fig. 2A,E,I). During active low-density growth, individual RMT lines displayed doubling times ranging from 14 to $21 \mathrm{~h}$ (Table I). When cells were grown at $37^{\circ} \mathrm{C}$, a condition that should inactivate the Tag protein, mitotic profiles were again observed with no evidence of myotube formation, suggesting that sufficient functional Tag was still present to drive cell division (Fig. 2B,F,J). In contrast, the addition of dox at the permissive growth temperature produced a much more profound effect on cell growth and the formation of myotubes. For the cell lines shown here, growth was dramatically reduced and no clear mitotic profiles were observed in the DAPI stained plates used for this analysis (Fig. 2C,G,K). Approximately 50\% of RMT461 cells converted to myotubes with dox treatment alone (Fig. 2C), and RMT631 cells arrayed themselves in fiber-like strands of individual cells with rare myotubes (Fig. 2G). RFT8 cells grew equally well at either 32 or $37^{\circ} \mathrm{C}$ (Fig. 2I,J), but as with the RMT lines, dox treatment clearly lowered cell density and also resulted in an increasingly flattened morphology (Fig. 2K).

The greatest degree of morphological differentiation was observed in cells with combined temperature shift to $37^{\circ} \mathrm{C}$ and dox addition. Under these conditions, no mitotic profiles were observed for any of the cell lines and by 1 week, all muscle-like lines had formed myotubes. For RMT461 and RMT631 cells this conversion was $>90 \%$ (Fig. 2D,H). Differentiated RMT461 and RMT631 cells produce long, multi-nucleated fibers, the majority of which are narrow in diameter, and accommodated only 1-2 nuclei in width for the length of the fiber. A smaller percentage of the fibers are wide near one terminus with 5-50 nuclei, and taper along their length to fibers with widely spaced individual nuclei. As shown in Figure 2L, RFT8 cells did not form any observed myotubes, but they did flatten and distribute with greater distance between nuclei suggesting a differentiated state. 

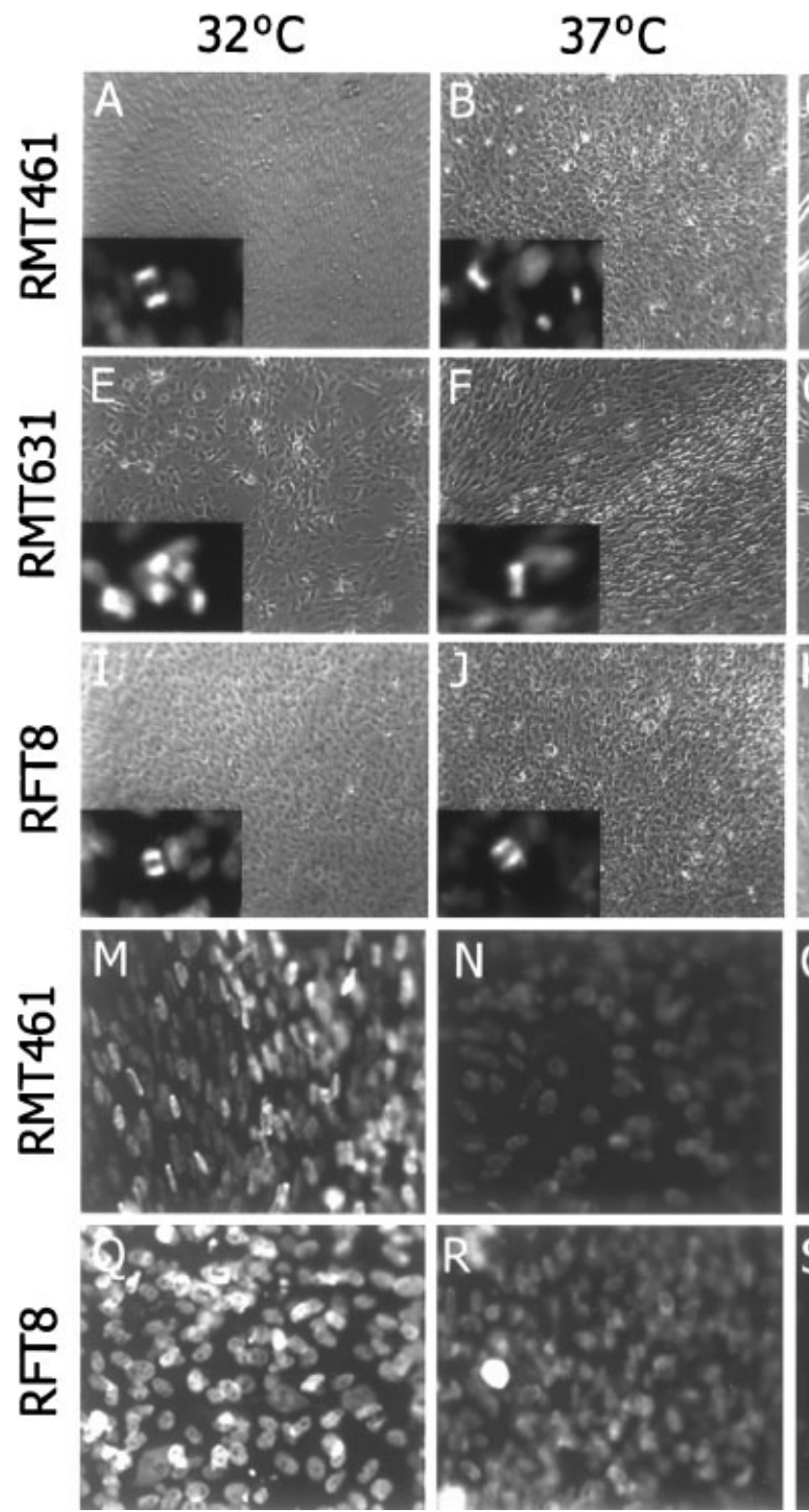

Fig. 2. Images of RMT and rat fibroblast-like tetracycline (RFT) cell lines under different growth and differentiation conditions. Labels at the top indicate the temperature and dox condition for each column of images while the labels on the left indicate the cell line shown across the row. Insets in some panels show magnified images of mitotic profiles revealed by DAPI staining in

Although these data are consistent with the predicted action of the NIT-Tag provirus, we sought to confirm changes in Tag production through the use of a mAb that recognizes the native form of Tag but not the denatured form of Tag at the non-permissive temperature, $37^{\circ} \mathrm{C}$. This mAb was employed to compare the levels of the Tag protein under each of the above conditions. The results for all RMT cell lines and RFT8 followed the same trend, and the results

$32^{\circ} \mathrm{C}+$ dox
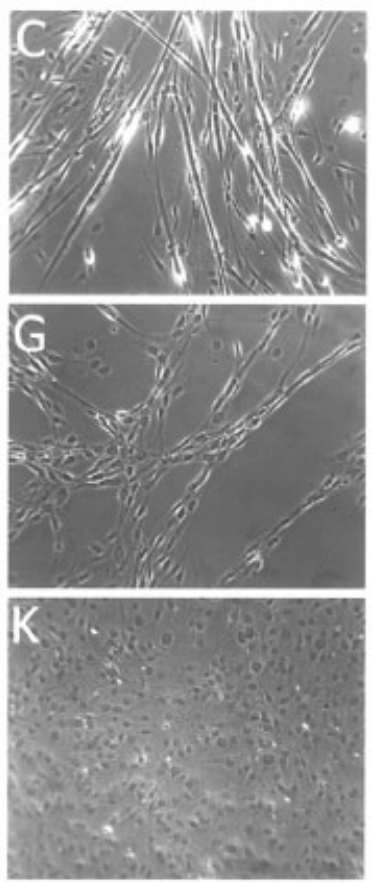

$37^{\circ} \mathrm{C}+$ dox
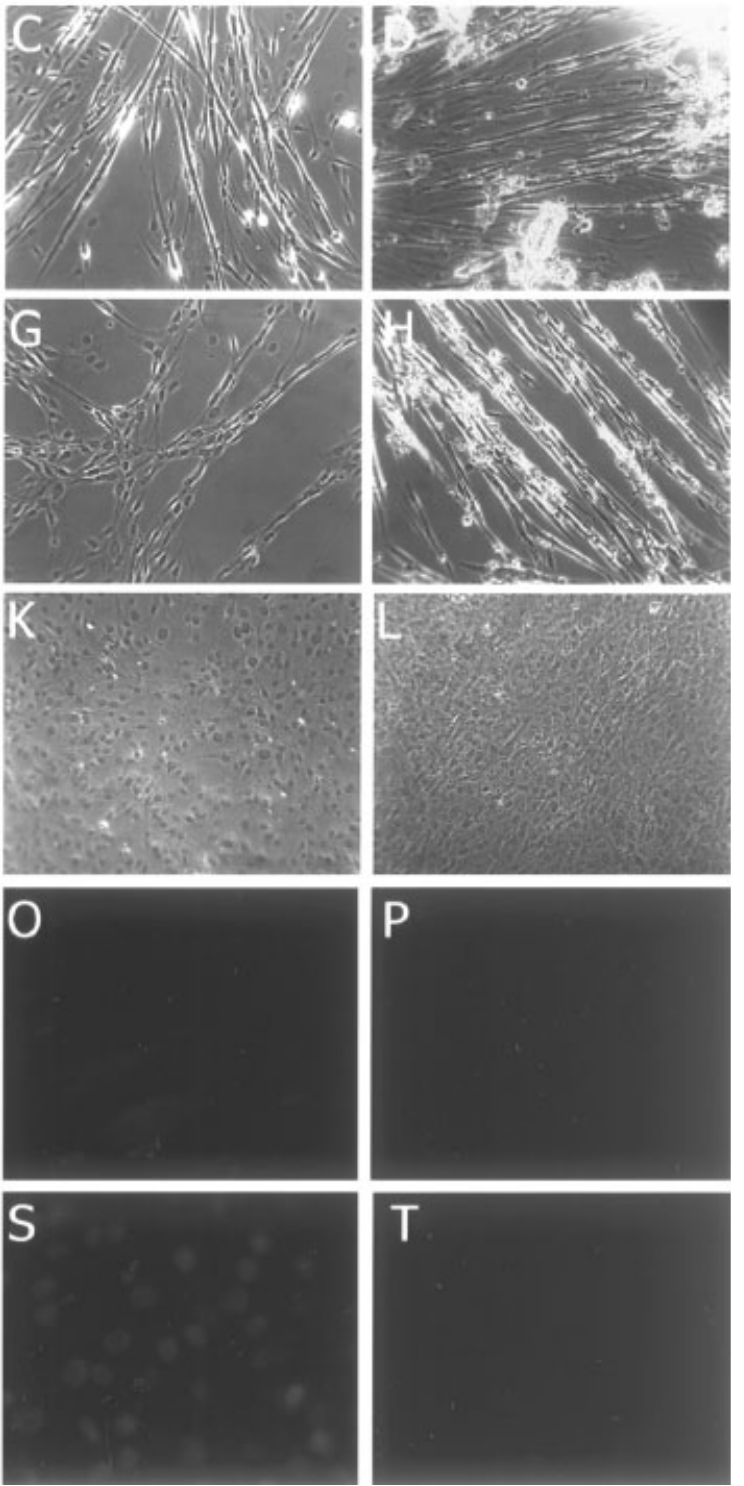

cell populations with active growth. A-L: $200 \times$ Brightfield images of individual cell lines grown under different conditions as labeled. M-T: $400 \times$ Fluorescent image of Tag immunostaining revealing changes in the immunopositivity of nuclei with changes in growth conditions.

are shown for lines RMT461 and RFT8 in Figures 2M-T. Nuclear localized Tag was clearly observed in essentially all growing cells at $32^{\circ} \mathrm{C}$ (Fig. 2M,Q). With the shift to $37^{\circ} \mathrm{C}$, a clear decrease in staining intensity is observed, although nuclear localized Tag is still readily apparent (Fig. 2N,R). Under the $32^{\circ} \mathrm{C}+$ dox conditions, Tag staining is dramatically reduced relative to either of the previous conditions (Fig. 2O,S). The low level observed at $32^{\circ} \mathrm{C}$ is 
TABLE I. Gross Characterization of Cell Lines

\begin{tabular}{lccccccc}
\hline Name/rep line & No. of SC & Morph & Het & Doub (in h) & Df. time (in days) & Fib/mon & Act. \\
\hline RMT22/221 & 9 & Myoblastic & - & 19 & $5-7$ & ++ & ++ \\
RMT46/461 & 3 & Myoblastic & - & 21 & $3-4$ & +++ & ++++ \\
RMT59/5951 & 4 & Myoblastic & - & 13 & $5-6$ & ++ & + \\
RMT62/6211 & 7 & Myoblastic & - & 14 & $4-5$ & ++ & +++ \\
RMT63/631 & 6 & Myoblastic & + & 15 & NA & - & +++ \\
RMT8 & - & Fibroblastic & NA & 14 & NA \\
\hline
\end{tabular}

Name, line name of the original isolate; rep line, representative subclone obtained by limiting dilution and used in most later analyzes; no. of SC, number of individual subclones obtained by limiting dilution and subject to analysis. RMT8 was not subcloned, but was selected based on comparison to other fibroblastic RMT lines 34, 55, 58, 64, and 70 not described. Morph, morphological appearance while growing; Het, differences in characteristics such as morphology and differentiation between subclones within a line. (-) Indicates no apparent differences; (+) indicates differences between clonal lines. Doub, approximate doubling time of the original isolate; Df time, number of days following initiation of differentiation to obtain maximal cell fusion, myofiber formation, and onset of spontaneous activity; Fib/mon, approximate number of cells participating in fiber formation versus cells that remain mononuclear at maximal differentiation. (-) No fiber formation, $(+)<20 \%$ nuclei in fibers, $(++) 20-50 \%,(+++) 50-90 \%,(++++)>90 \%$. Act, spontaneous activity following majority fiber formation. $(+)$ Very rare active fibers, $(++)$ occasional active fibers, $(+++)$ frequent active fibers, $(++++)$ many active fibers.

aBecause of proximal colonies in original selection of the isolate, lines 59 and 62 underwent an intermediate round of clonal selection prior to subcloning by limiting dilutions.

even further reduced under the most favorable condition for differentiation, $37^{\circ} \mathrm{C}+$ dox (Fig. 2P,T). The above data provides evidence that the combination of temperature shift and dox treatment very effectively blocks the transforming function of the Tag protein.

\section{Transcription Factor Immunostaining}

To further establish the identity of these cell lines both in the proliferating and differentiated state we examined the expression of Pax7 and the MTFs (MyoD, Myf-5, MRF4, and myogenin). Pax7 has been characterized as specific to undifferentiated mononuclear muscle precursors known as satellite cells [Seale et al., 2000]. MyoD and Myf-5 are predominantly associated with the commitment of differentiating mononuclear cells to myogenic determina- tion while MRF4 and myogenin are believed to be involved in myoblast terminal differentiation [Buckingham et al., 2003]. Analysis of these markers is shown in Figure 3. In Figure 3A-D, RMT461 cells in different growth conditions were processed for Pax7 (red) and Myf-5 (green) immunostaining. In Figure 3A,B, respectively, proliferating and confluent RMT461 cells are strongly nuclear positive for both $\operatorname{Pax} 7$ and Myf-5 (co-localization indicated by yellow color). After differentiation (Fig. 3C,D), Pax7 intensity is significantly decreased and appears to be lost altogether in the nuclei of differentiated myotubes, whereas Myf-5 continues to be observed at a high-levels in the nuclei, and, to a lesser extent, the cytoplasm, of both mono- and multinucleated cells. Each of the RMT lines followed the same pattern of marker expression as the RMT461 line.
Fig. 3. Immunocytochemical analysis of differentiation of cultured cell lines in different growth conditions. A-D: Immunostaining with Pax7 (red), Myf-5 (green), and nuclear DAPI stain (blue in 3D only). A: Staining of proliferating RMT461 cells. The inset shows a magnified section of $(A)$ with red and green channels separated; (B) staining of confluent RMT461 cells; (C) staining of differentiated RMT461 cells; (D) a magnified image of differentiated RMT461 cells with contrast-intensified Pax7 signal (red), Myf-5 (green), and nuclear DAPI stain (blue) revealing rare cells not incorporated into myofibers that retain Pax7 positivity (fuchia color indicates colocalization of red, green, and blue signal highlighted by a white arrow) while other nuclei in myofibers have little or no Pax7 (aqua and blue shades indicate overlap of green and blue stains and are highlighted by orange arrows). E-H: Immunostaining for MRF4 (green) and nuclear stain with DAPI (blue). E: Proliferating RMT461 cells; (F) confluent RMT461 cells. Inset shows the green MRF4 signal visible in only a few scattered nuclei; (G) differentiated RMT461 cells; and $(\mathrm{H})$ a magnified region of $(\mathrm{G})$ showing separate nuclei in blue (upper panel) and MRF4 signal in green (lower panel). I-Q: Immunocytochemical analysis of MyoD (green) and myogenin (red) in cultured cell lines in different growth conditions. Blue is nuclear DAPI stain. I-K: RMT461 cells. I: Proliferating RMT461 cells. Inset shows the green channel alone revealing MyoD staining that is somewhat masked in the merged image by DAPI co-stain; (J) confluent RMT461 cells. Inset shows the red channel alone revealing myogenin staining in a large proportion of cells; (K) differentiated RMT461 cells. L-N: RMT631 cells; (L) proliferating RMT631 cells; (M) confluent RMT631 cells; and (N) differentiated RMT631 cells. O-Q: RMT221 cells. O: Proliferating RMT221 cells; (P) confluent RMT221 cells; (Q) differentiated RMT221 cells. Images are at $200 \times$ and insets and magnified images (Diff- $800 \times$ ) are at approximately $800 \times$ magnification. 
A similar analysis of MRF4 (green) with accompanying nuclear DAPI stain (blue) is shown in Figure 3E-H. Proliferating RMTs displayed no detectable expression of MRF4 (Fig. 3E). At high cell density, we observed rare cells that were positive for MRF4 (Fig. 3F and inset). In contrast, after differentiation all of the RMT lines displayed essentially uniform MRF4 positive staining in the nuclei and weak expression the cell body of myotubes and mononuclear cells (Fig. 3G,H). Again, each of the RMT lines followed a similar pattern of marker expression as the RMT461 line.

The expression of MyoD and myogenin were analyzed together and the results are shown for RMT461, RMT631, and RMT221 cell lines (Fig. 3I-Q). MyoD-positive signal (green) was observed in the nucleus and to a lesser extent, the cytoplasm, of all RMT cells at all phases of growth (Fig. 3I-Q). Unlike MyoD, during active proliferation, myogenin-positive immunostaining (shown in red) was a rare occurrence
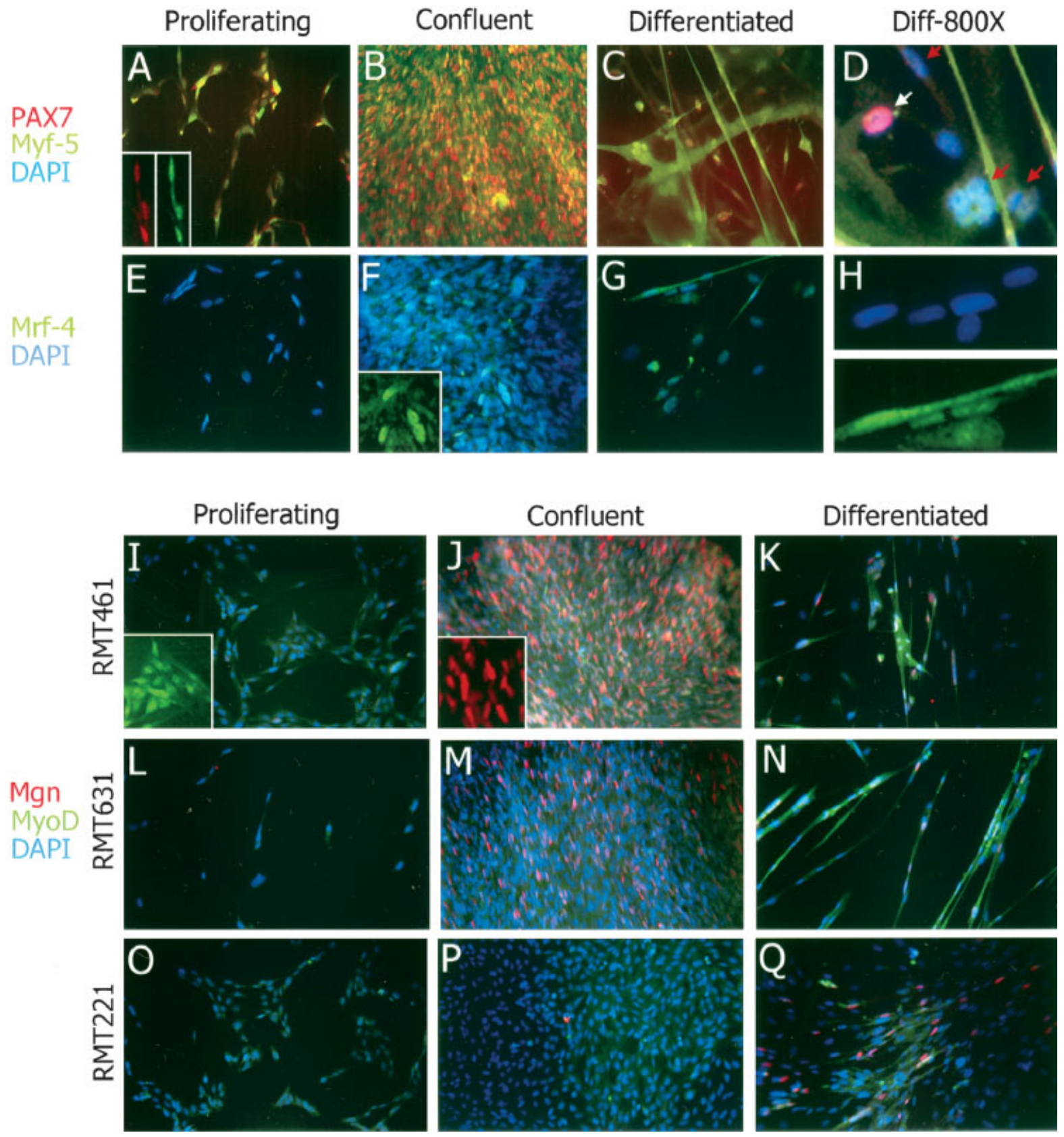

Fig. 3. 
for any of the RMT lines (Fig. 3I,L,O). In confluent RMT cultures, however, notable differences were observed in myogenin expression that were not seen with other MTFs described above. As shown in Figure 3J,M, the RMT461 and RMT631 lines displayed a significant increase in myogenin expression, while other lines, like RMT221, showed rare positive cells (Fig. 3P). After 1 week of differentiation, the overwhelming majority of RMT461 and RMT631 mononuclear cells and fibers were positive for nuclear myogenin signal (Fig. 3K,N). The RMT221 line, which was slower to differentiate, also displayed many cells and fibers that were strongly positive for myogenin at the 1-week time-point (Fig. 3Q). Taken together, these data suggest that RMT cells possess the characteristics of a muscle precursor cell known as an "activated satellite cell" that progresses through a predictable course of differentiation to become a mature myotube. It is noteworthy that a parallel analysis of transcription factor expression was performed on RFT cells, and under each growth condition, no positive signal was observable (data not shown).

After extensive testing of each of the RMT cell lines under various conditions, we could assign a generalized "differentiation" ranking to the cell lines that combined speed of differentiation, extent of morphological maturation (mononuclear cells vs. myotubes), and degree of differentiation-marker expression. The ranking is as follows with the most "differentiatable" first: RMT461 > RMT631 > RMT6211 > RMT221 > RMT5951. Many of the features of each of these cell lines are summarized in Table I.

Preliminary experiments with differentiated RMT cells revealed that they not only differentiated to produce abundant myotubes, but that these myotubes also display widespread spontaneous contractile activity. Contractile activity of individual lines roughly paralleled the differentiation ranking, with RMT461 displaying vigorous contractile activity the most rapidly (see also Table I). Based on these observations, we chose to focus on the RMT461 cells and make a more detailed comparison of this line with the characteristics of isolated primary muscle cells from rat embryos.

\section{Primary Versus RMT461 Immunostaining}

During low-density growth, both primary muscle cells and RMT461 express abundant
MyoD (Fig. 4). In contrast, few cells appear to be myogenin positive in either primary cell cultures or RMT461 cells, consistent with observations of RMT lines above. Upon differentiation, both primary muscle cells and RMT461 cells fuse to form MyoD positive myotubes and myogenin expression is dramatically increased relative to non-differentiated cells and appears to be present in essentially all of the myonuclei.

After differentiation, sarcomeric myosin is expressed throughout the cytoplasm of primary and RMT461 myotubes in a similar manner (Fig. 4). Typically, both primaries and RMT461s begin to spontaneously contract within $24 \mathrm{~h}$ of myotube formation. One notable difference between primary myotubes and the immortalized cell lines in general, is that the cell lines tend to make smaller myotubes that contain fewer myonuclei (Fig. 4 compare myogenin stained primary myotubes with 461 myotubes). Varying differentiation media conditions does not seem to alter this characteristic and it is currently not known whether this is an intrinsic property of the cell lines or is due to heterogeneity of the cell population in the primary cell preparation.

\section{nAChR Clustering}

nAChRs are ligand-gated ions channels that transmit excitatory signals from motor neurons to stimulate skeletal muscle contractile activity. During early muscle development nAChRs are expressed throughout the membrane, but as myotubes mature, receptors begin to aggregate (cluster) spontaneously. This process of nAChR clustering is dramatically increased with the arrival of pre-synaptic motor terminals which secrete a neural specific form of the synapse organizing protein, agrin. Since $n A C h R$ clustering is a fundamental precursor to the processes of activity-dependent signaling at the neuromuscular junction, we sought to further characterize the maturation of RMT myotubes by evaluating their ability to cluster nAChRs. When RMT461 myotubes were fluorescentlylabeled with $\alpha$-BTX, these mature myotubes formed nAChR clusters that were comparable in size and number to primary myotubes (Fig. 5A). This observation suggests that the signaling pathway for the formation of neuromuscular junctions remained intact in RMT461 cells.

As a further test of the integrity of this synapse forming pathway we treated RMT461 

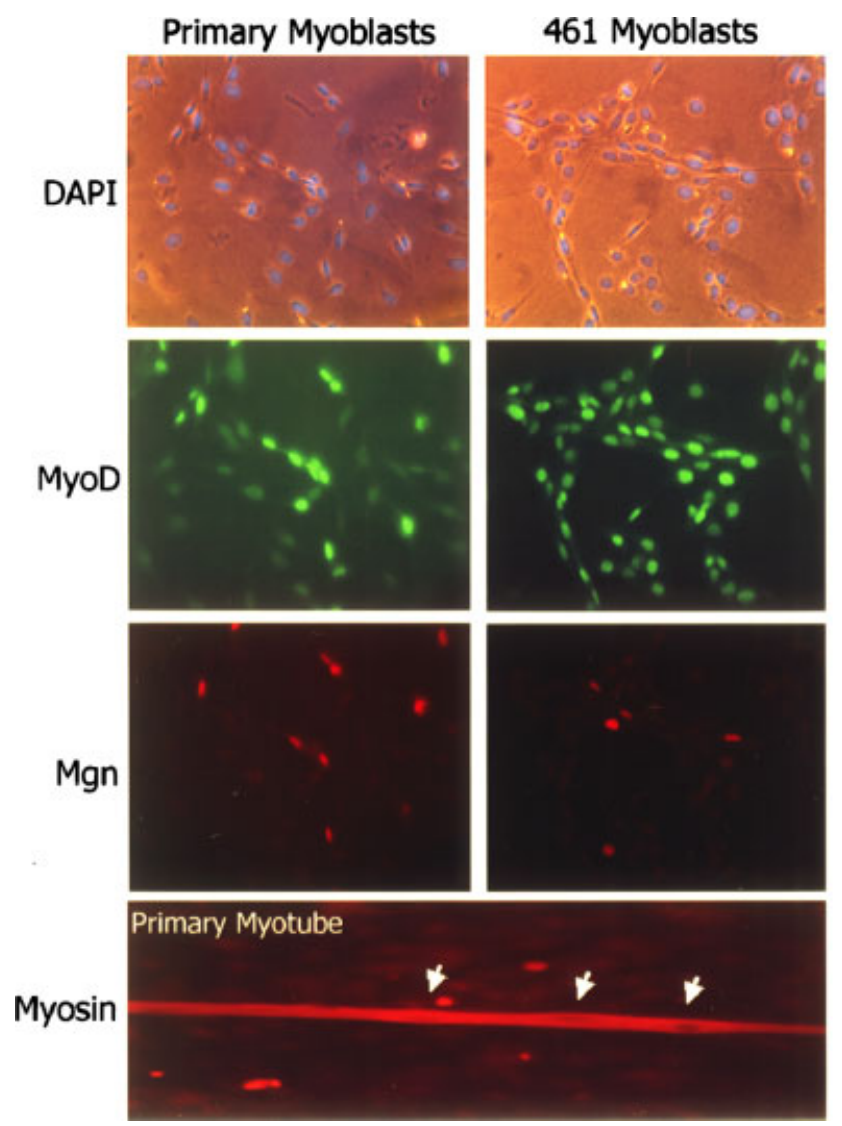

Fig. 4. Expression of MyoD, myogenin, and myosin in myoblasts and myotubes from rat primary muscle cells and RMT461 cells. Top panel: Brightfield images with superimposed, DAPI stained nuclei of growing myoblast, and myotubes 7 days after differentiation. The middle two panels are the same images as in top panel that have been double labeled for MyoD (green)

myotubes with conditioned media from cells expressing either a secreted or a membrane bound form of agrin. Compared with control non-conditioned myotubes, those that were exposed to conditioned media containing secreted agrin (cAg4-8) displayed visibly increased numbers of nAChR clusters (Fig. 5B) whereas myotubes treated with conditioned media from cells expressing membrane bound agrin (Ag124-8) showed no evident increase in nAChR clustering. Taken together these data indicate that the components necessary for the initial stages of synapse formation are intact in the immortalized cell lines.

\section{Activity-Dependent Regulation}

In differentiating cultured primary myotubes and RMT cell cultures, contractile activity is readily observed; however, this characteristic is difficult to quantify. Although direct compara-
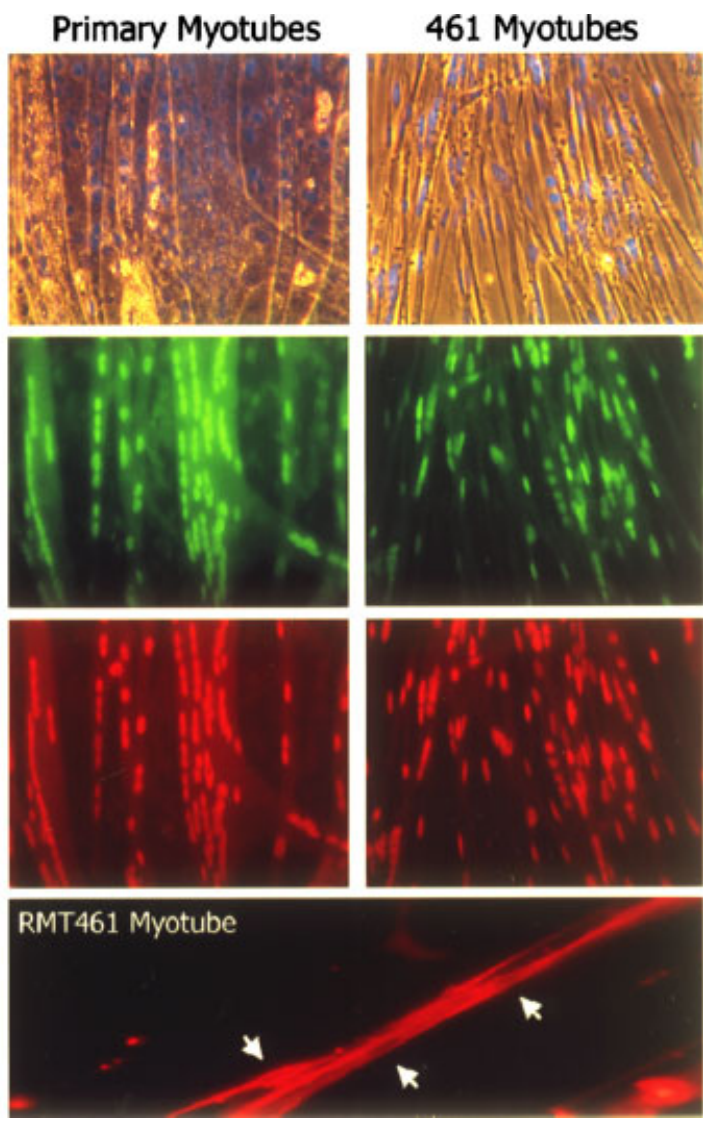

and myogenin (Mgn) (red). The bottom panel shows myosin positive myotubes from primary and RMT461 cells, respectively. Note that the nuclei are myosin negative in both cases (arrow heads). Images are at $200 \times$ magnification. [Color figure can be viewed in the online issue, which is available at www. interscience.wiley.com.]

tive measurements of activity are problematic for a variety of reasons, it is possible and also of perhaps of greater utility to quantify the down stream effects of activity on myofiber biology. A number of genes and their protein products have been found to be rapidly and quantifiably changed in response to electrical stimulation both in vitro and in vivo. To better assess the usefulness of the RMT461 cell line as an alternative model system for studying muscle biology, we examined several genes with activity-dependent regulation by RNase-protection assay and Western blot analysis. Among the gene products examined were cell cycle regulators, $\mathrm{Rb}$ protein and $\mathrm{p} 21$, the four MTFs, the five subunits $(\alpha, \beta, \delta, \gamma$, and $\varepsilon)$ of the nAChR, and MuSK, a muscle specific tyrosine kinase required for motor endplate formation.

We have previously shown that $6 \mathrm{~h}$ of electrical stimulation is sufficient to produce significant 


\section{A}

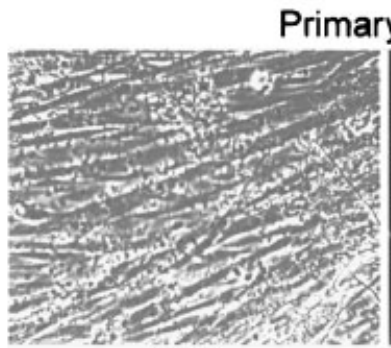

Bright
Primary Myotubes

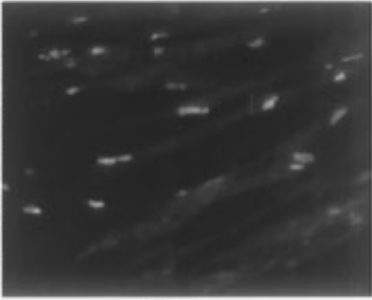

$\alpha \mathrm{BTX}$

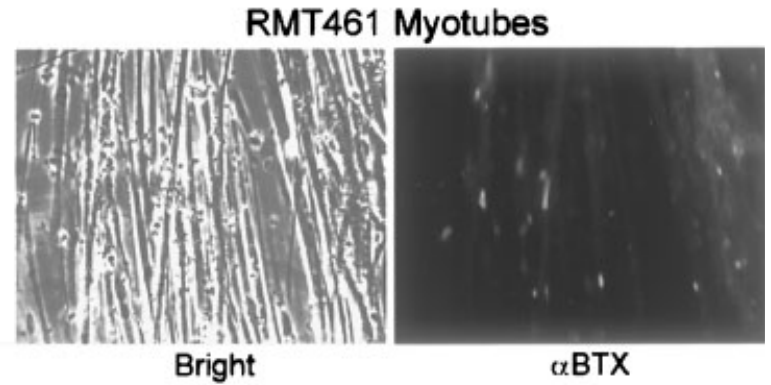

Bright $\alpha \mathrm{BTX}$
B

\section{Control}
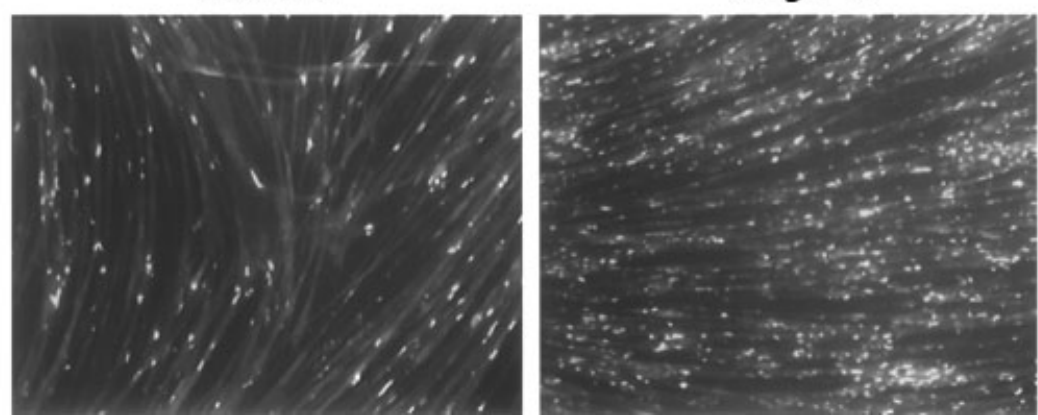

Ag12-4-8

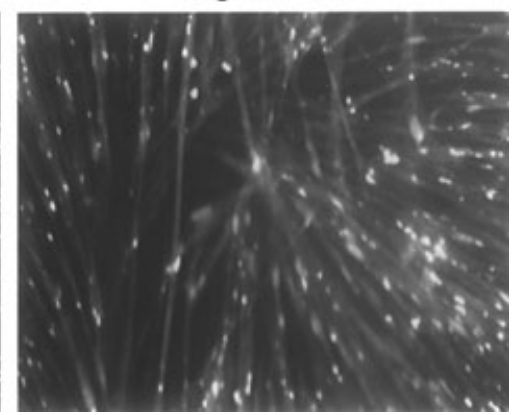

Fig. 5. nAChR clustering in primary and RMT461 myotubes. A: After 1 week of differentiation, primary and RMT461 myotubes were incubated with Texas red $\alpha$-bungarotoxin $(\alpha-B T X)$ to visualize $\mathrm{nAChR}$ clustering. Brightfield images are included to indicate the relative density of myotubes on each plate. Images are at $200 \times$ magnification. B: Agrin induced nAChR clustering in RMT461 myotubes. After 1 week of differentiation, myotubes were incubated for $24 \mathrm{~h}$ with unconditioned medium (control), conditioned media from myotubes transfected with a secreted form of agrin (c-Ag4-8), or media from myotubes transfected with a membrane bound form of agrin (Ag12-4-8). Agrin induced clustering was evaluated qualitatively by comparing the relative level of clustering in four randomly selected fields for each condition tested. Images are at $100 \times$ magnification. changes in gene transcription in primary myotubes [Macpherson et al., 2002]. In the present study, RNase protection assays show that after $6 \mathrm{~h}$ of electrical stimulation transcripts for Rb and p21 are not acutely affected by activity in primary myotubes, but decrease in RMT461 myotubes (Fig. 6A,B). Interestingly, preliminary data from our lab indicate that mRNA for both Rb and p21 increase significantly in denervated whole muscle, and these increases appear to be suppressed by electrical stimulation (unpublished data). Consequently, the observation that the levels of $\mathrm{Rb}$ and p21 in primary myotubes are less responsive to the effects of electrical stimulation than in whole muscle or RMT461 myotubes may reflect the heterogeneity of the cell population in primary cultures.

While the role of cell cycle regulators in activity-dependent gene regulation remains to be determined, many reports have implicated myogenin as an important MTF that not only is regulated by muscle activity, but is also involved in regulating $\mathrm{nAChR}$ gene expression in response to muscle depolarization [Neville et al., 1992; Mendelzon et al., 1994; Gundersen et al., 1995; Tang et al., 2001]. Six hours of electrical stimulation produced significant decreases in myogenin mRNA in primary myotubes, but only slightly decreased myogenin mRNA in RMT461s (Fig. 7A). This was also true for at least two of the other RMT cell lines (not shown). In contrast, myogenin protein was regulated in a similar manner in primary and RMT461 myotubes (Fig. 7B). These data suggest that although muscle activity can reduce myogenin expression in both primary and immortalized muscle lines, the mechanisms contributing to this reduction may differ between primary and immortalized cell lines.

Since changes in the levels of protein expression, rather than RNA, are more likely to impact down stream targets of transcription factors we also checked for changes in the protein levels of the other MTFs (MyoD, Myf-5, and MRF4). When protein levels for each of these proteins 
A
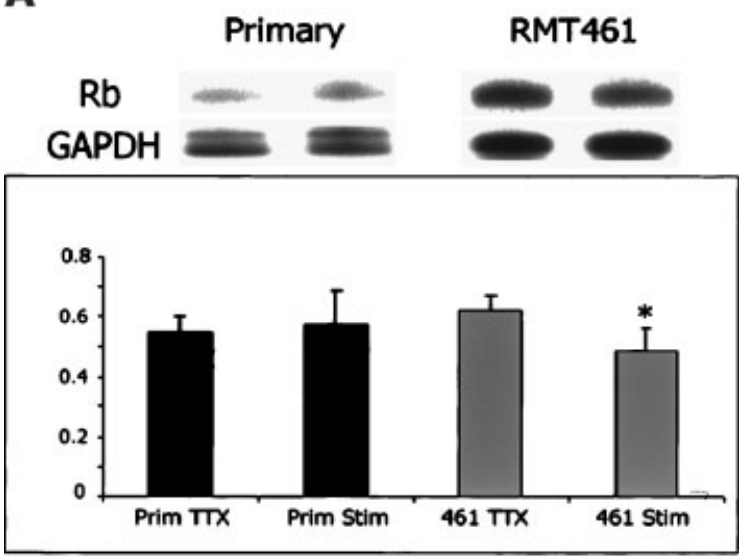

B

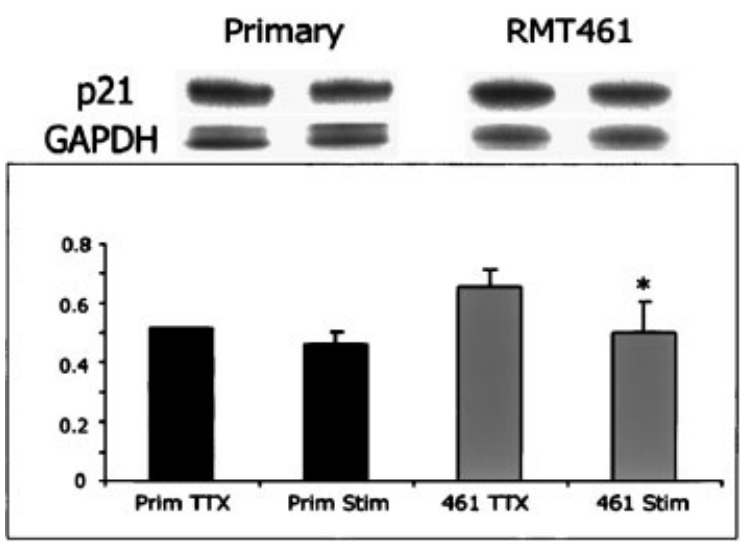

Fig. 6. Effects of short-term electrical stimulation on the levels of retinoblastoma $(\mathrm{Rb})$ and p21 mRNA in primary and RMT461 myotubes. RNase protection assays were used to assay for changes in the levels of $\mathrm{Rb}(\mathbf{A})$ and p21 (B) mRNA in primary (black bars) and RMT461 myotubes (gray bars) after $6 \mathrm{~h}$ of electrical stimulation. Changes in RNA levels are compared to non-stimulated myotubes that were maintained in media containing tetrodotoxin (TTX). At the top of each graph are representative RNase protections. Values presented are the average of two experiments and each experiment was performed in duplicate. For each protection assay, levels of Rb and p21 mRNA were normalized to the level of expression of glyceraldehyde-3-phosphate dehydrogenase (GAPDH). Bars represent mean \pm SD. ${ }^{*} P<0.05$, significantly different from within group controls (TTX).

was assessed after $6 \mathrm{~h}$ of electrical stimulation no substantial effect was observed in either rat primary or RMT461 myotubes (Fig. 7C-E). Whether these proteins are affected by longer periods of muscle activity will require further experimentation.

Activity-dependent regulation of the $\mathrm{nAChR}$ subunit genes has been well documented both in whole muscle and in primary muscle cells [Goldman et al., 1988; Witzemann et al., 1991;
Chahine et al., 1993; Dutton et al., 1993; Bessereau et al., 1994]. After $6 \mathrm{~h}$ of electrical stimulation, we observe suppression of the mRNA for each of the nAChR subunits genes in the RMT461 cell line (Fig. 8A-E). Furthermore, as can be seen for the gamma and alpha subunits, the levels of suppression that are achieved in the cell line are similar to those in primary myotubes (Fig. 8D,E). As a further test of activity-dependent regulation in the RMT lines we probed for changes in MuSK, which has also been shown to be regulated by muscle activity [Bowen et al., 1998]. Similar to the $\mathrm{nAChRs,}$ $6 \mathrm{~h}$ of electrical stimulation caused a significant decrease in the level of MuSK mRNA in both primary and RMT461 myotubes (Fig. 8F).

Collectively, these data indicate that morphological, physiological, and biochemical characteristics of primary myoblast cultures and RMT cells are very similar and that RMT cells are likely to be a useful alternative model system to study muscle differentiation, maintenance, and activity in vitro.

\section{DISCUSSION}

The goal of this study was to produce a conditionally immortalized muscle cell line for the purpose of investigating processes of activitydependent gene regulation. With the use of a temperature-sensitive, tetracycline-regulated retroviral vector we successfully generated a number of these cell lines from embryonic rat muscle tissue that display both the morphological and contractile characteristics of isolated primary myotubes. These lines have the capacity to proliferate under a variety of growth conditions and yet assume intrinsic muscle properties after stimulation to differentiate. Several of these RMT cell lines and the RMT46-derived lines in particular, have demonstrated reproducible contractile activity through passage 15 even when combined with limited-dilution subcloning or re-infection and selection.

The NIT vector has two potential advantages over many other tetracycline-regulated vectors in that it is more rapidly regulated by the addition or removal of Tet-analogs than many other vectors and NIT has no evident toxicity in cultured cells with repeated passage. This may stem from a lowered level of TTA protein indirectly expressed from the viral LTR via the IRES element (generally $2-5 \%$ of the protein encoded in the up stream position) that may 
A

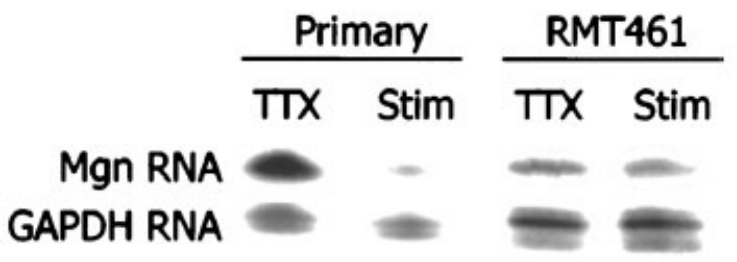

B

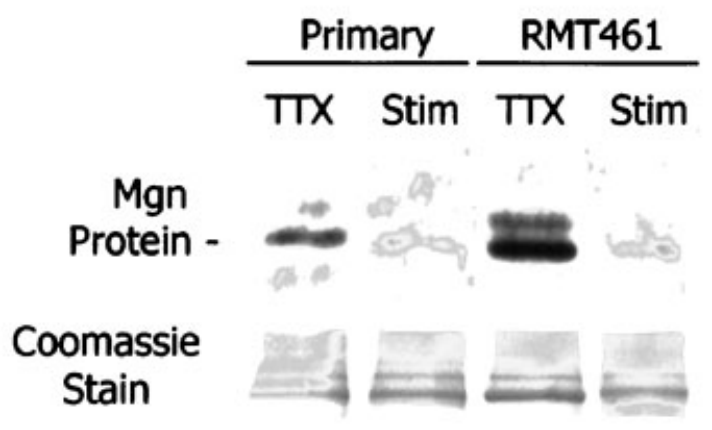

D

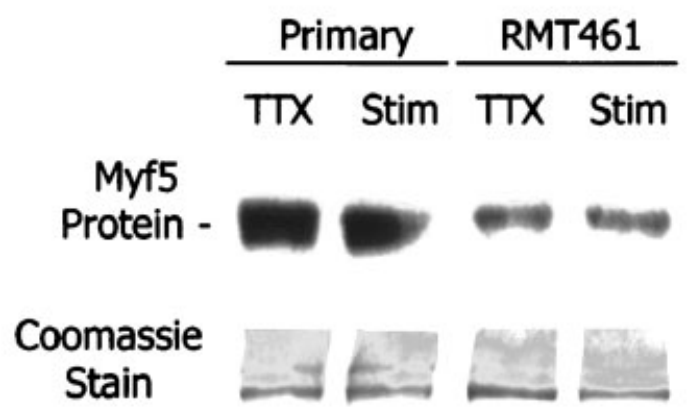

Fig. 7. Changes in myogenic transcription factors (MTF) after short-term electrical stimulation. A: RNase protection assays were used to assay for changes in levels of myogenin (Mgn) mRNA in primary myotubes (black bars) and RMT461 myotubes (gray bars) after $6 \mathrm{~h}$ of electrical stimulation. Changes in RNA levels are compared to non-stimulated myotubes that were maintained in media containing TTX. Representative RNase protections are presented at the left of the graph. Values presented are the average of two experiments and each experiment was performed in duplicate. For each protection assay, levels of Mgn

both reduce toxicity and speeds responsiveness to Tet-analogs. Even though the level of TTAtransactivator production is low, it is still likely to be saturating with respect to activation of the To response promoter. In the absence of tetracycline analogs, the NIT vector typically provides higher levels of transgene expression at

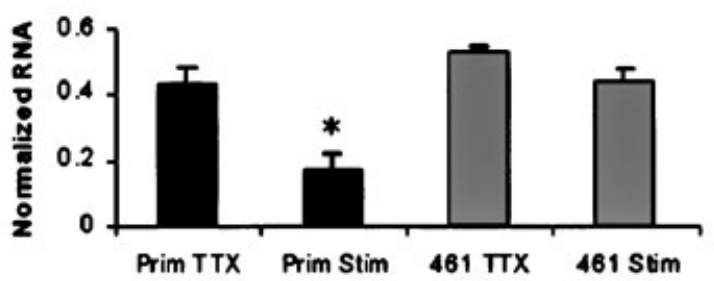

C

$\frac{\text { Primary }}{\pi \times \quad \text { Stim }} \frac{\text { RMT461 }}{\pi \times \quad \text { Stim }}$

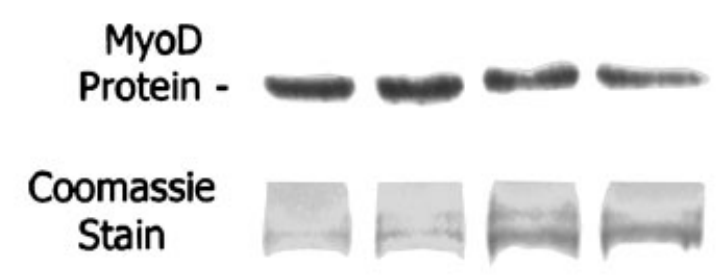

E

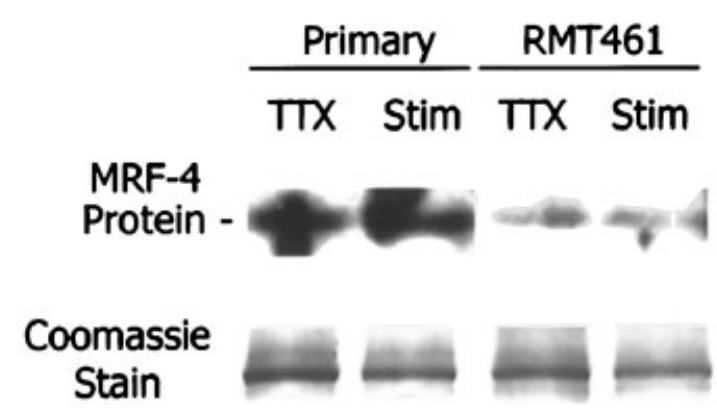

mRNA were normalized to the level of expression of GAPDH. Bars represent mean \pm SD. $* P<0.05$, significantly different from within group controls (TTX). B-D: Representative Western blots of changes in myogenin (B), MyoD (C), Myf-5 (D), and MRF4 (E) protein after $6 \mathrm{~h}$ of electrical stimulation. Coomassie blue stained gels are shown as an additional control for total protein loading ( $20 \mu \mathrm{g} /$ lane). For each figure, samples from control (TTX) and electrically stimulated (Stim) primary myotubes are presented in the first two lanes, respectively and samples from RMT461 myotubes are presented in the second two lanes.

low copy than direct expression from strong viral promoters such as the hCMV, sCMV, or RSV promoters (unpublished observations).

Two general morphologies were observed in the original isolated colonies: the spindleshaped colonies that produced the RMT cell lines, and more numerous fibroblast-like colo- 
$\mathbf{A}$
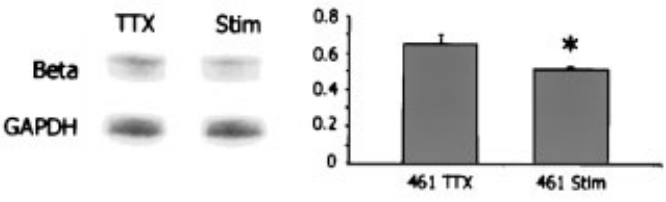

B
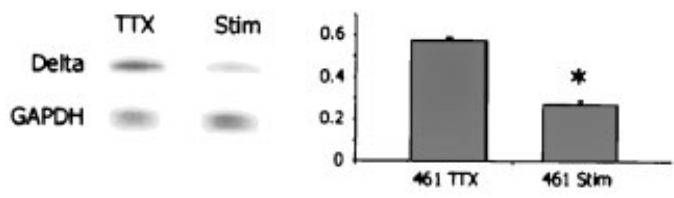

C
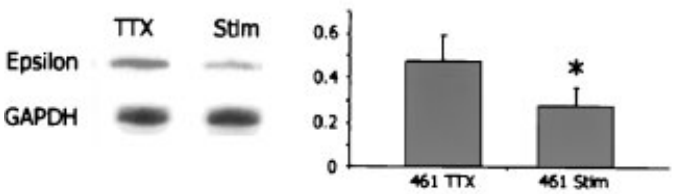

Fig. 8. Activity-dependent changes in RNA levels for $n A C h R$ subunits and muscle specific kinase (MuSK) measured by RNase protection assay. Values for RMT461 myotubes are indicated by gray bars and values for primary myotubes are indicated by black bars. "TTX" label indicates non-stimulated cultures and "Stim" label indicates cultures electrically stimulated for $6 \mathrm{~h}$. Representative RNase protections are presented to the left of each graph. A: Assay of nAChR $\beta$ subunit RNA in RMT461 myotubes; (B) assay of nAChR $\delta$ subunit RNA in RMT461 cells; (C) assay of nAChR $\varepsilon$ subunit RNA in RMT461; (D) comparative assays of

nies such as RFT8. Although the RFT cell lines are described as "fibroblast-like" and do not form myotubes under the conditions used in this report, it should not be assumed that these cells are fibroblasts. They may instead derive from any of the other cell types in the original preparation or may be a muscle-resident cell that is not yet committed to the muscle lineage.

With regard to RMT cell lines such as RMT461, the evidence presented in this report strongly suggests that it displays characteristics of committed muscle progenitor cells known as "activated" satellite cells. Pax7 is a hallmark of satellite cell specification in general [Seale et al., 2000], and co-expression of the MTFs Myf-5 and MyoD places these cells squarely within the activated category since "quiescent"
D
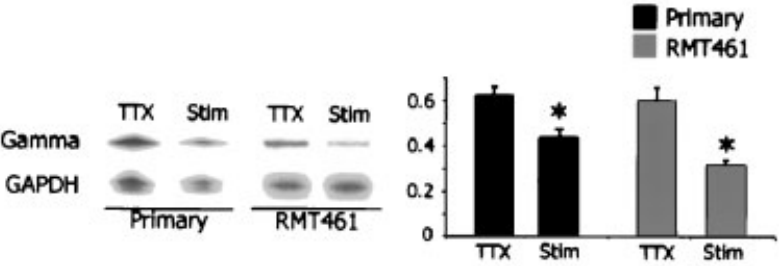

$\mathbf{E}$
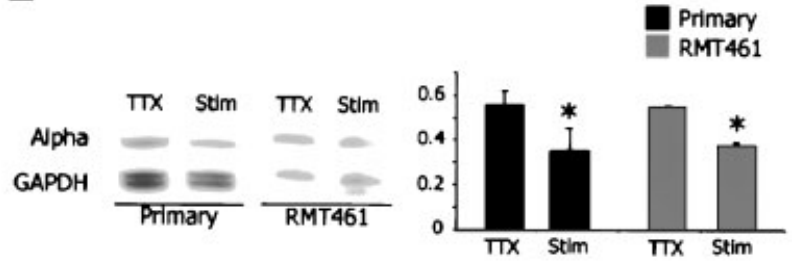

$\mathbf{F}$

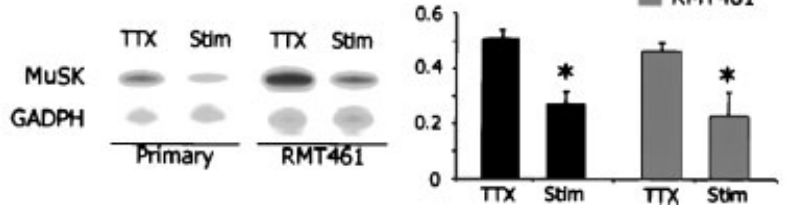

nAChR $\gamma$ subunit RNA in RMT461 myotubes and primary myotubes; (E) comparative assays of $n A C h R ~ \alpha$ subunit RNA in RMT461 myotubes and primary myotubes; (F) comparative assays of MuSK RNA in RMT461 myotubes and primary myotubes. Values presented are the average of two experiments, each performed in duplicate. For each protection assay, the respective level of mRNA was normalized to the GAPDH expression level. Bars represent mean \pm SD. ${ }^{*} P<0.05$, significantly different from within group controls (TTX).

satellite cells are generally considered negative for MTF expression [Seale et al., 2001]. An interesting feature of the RMT cell lines is that differentiation from mononuclear "activated satellite" cell to mature myofiber is marked by an apparent step-wise progression that is not as clearly delineated in other cell lines or primary cultures. One example of this is the onset of widespread myogenin expression in confluent RMT461 and RMT631 cultures that can be trypsinized, re-passaged, apparently resume mononuclear growth, and later, differentiate in a normal manner. MRF4 expression, on the other hand, does not increase substantially in the majority of dense RMT461 and RMT631 cells but is instead observed at high levels only after fusion is well underway. This difference 
suggests that MRF4 expression may indeed be an indicator of terminal differentiation whereas myogenin expressing cells, given the proper stimulus, can abort the differentiation program and return to a less differentiated state relatively unchanged. In Figure 9 we have summarized the markers characteristic of each of these steps, and propose a transient developmental stage for the activated cell termed the "queued" cell that represents a cell that has progressed far along the differentiation pathway, but not yet reached the point-of-no-return toward terminal differentiation.

Figure 9 also summarizes changes in the expression of the RNAs and proteins examined in differentiated myofibers with and without electrical activity. We have shown that, with the exception of subtle differences, the cell line RMT461 displays activity-dependent regulation of several muscle-expressed proteins including transcription factors, transmembrane receptors, and other proteins in a manner that suggests many similarities with primary muscle cells. Preliminary data from experiments performed on some of the other RMT cell lines indicate they also maintain contractile regulation similar to RMT461 and primary myotubes.

Possibly the best characterized activitydependent genes in skeletal muscle are those of the nAChR [Goldman et al., 1988; Witzemann et al., 1991; Chahine et al., 1993; Dutton et al., 1993; Bessereau et al., 1994]. The expression of these genes generally increases with muscle inactivity, and decreases when muscle cells are functionally active. Although a number of signaling pathways have been implicated in regulating these processes [Klarsfeld et al., 1989; Huang et al., 1992; Chahine et al., 1993; Mendelzon et al., 1994; Tang et al., 2001; Macpherson et al., 2002], the physiological details of how the regulatory pathways interact have not been unraveled. One of the problems in resolving these questions is the difficulty in large scale access to the nuclei of mammalian muscle preparations. The development of readily available muscle cell lines that maintain the same functional characteristic as primary cells should prove to be a valuable resource in addressing some of these issues.

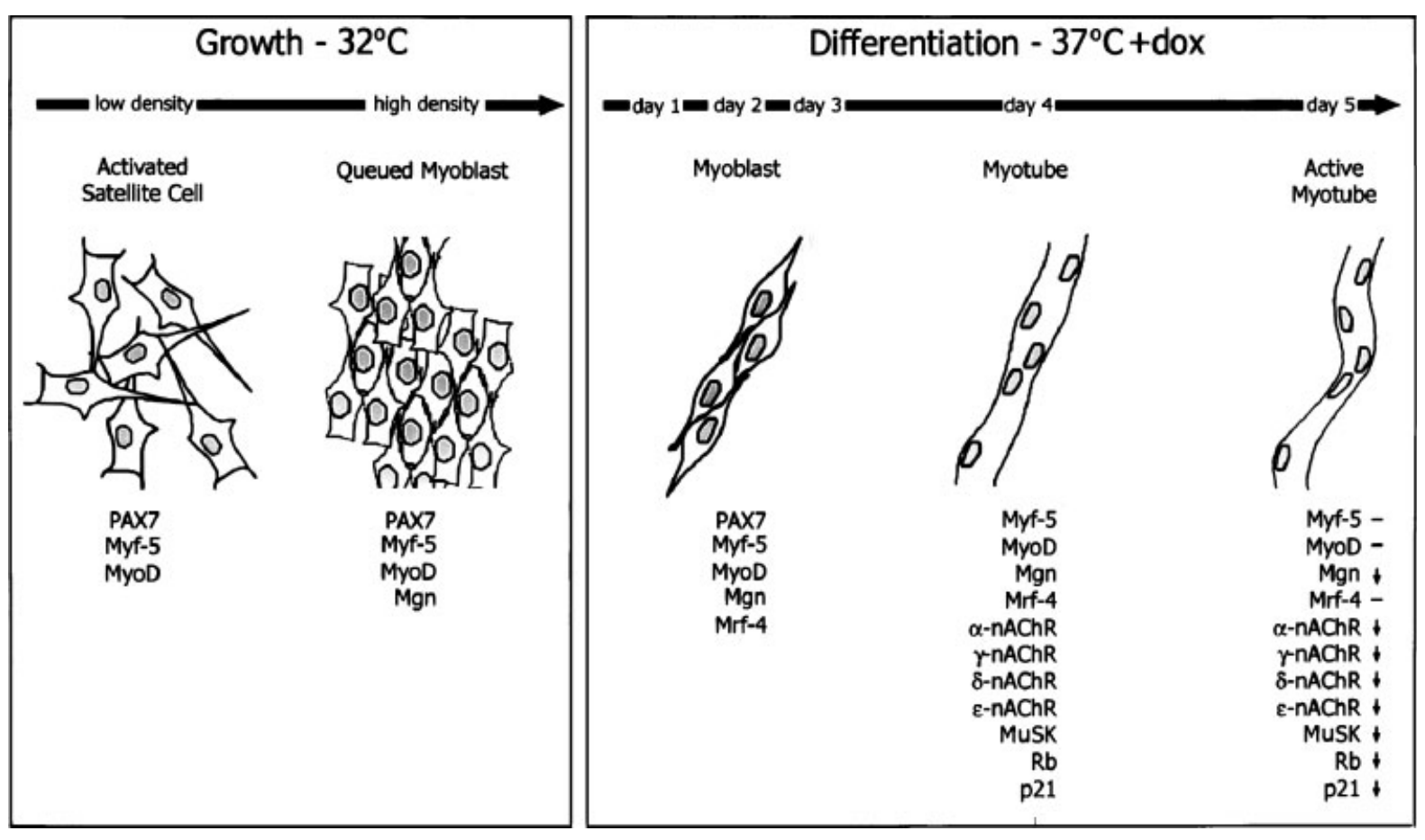

Fig. 9. Schematic of different stages of RMT461 differentiation, marker expression, and changes in gene expression/protein content with electrical activity. In the left panel, RMT cells are depicted during low- and high-density growth. Marker names below each category of cells indicates gene products found expressed at that developmental stage. Expression levels of nAChRs, MuSK, Rb and p21 were only evaluated in myotubes. At the far right, arrows and dashes associated with gene products indicate expression changes with electrical activity. 
One of the differences between primary cells and the immortalized cell lines appears to be in the regulation of $\mathrm{Rb}$ and $\mathrm{p} 21$ in response to electrical stimulation shown in Figure 6. The observation that $\mathrm{Rb}$ and $\mathrm{p} 21$ do not appear to be regulated by electrical stimulation in primary cell cultures may simply reflect the differences in the cell populations present in these cultures. Cultures from immortalized cell lines are composed of clonal myogenic cells, whereas primary cultures are heterogeneous in composition with a large percentage of the cells presenting a morphology suggesting fibroblastic origin [Rando and Blau, 1994 and clonal populations this study]. Since fibroblasts and other mononuclear cells do not possess the contractile machinery of myofibers yet do express $\mathrm{Rb}$ and $\mathrm{p} 21$, the presence of such large populations of cells in the primary muscle preparations would significantly dilute any observable effect of muscle activity. Regardless of the explanation for this difference between primary and RMT cultures, the above observations highlight one of the advantages of performing experiments with a pure population of cells when asking specific questions about the regulation of genes that are expressed in multiple cell types. In addition, because of the purity of the cell lines, they have been used as an enriched protein source to ask questions about protein phosphorylation [Tang et al., in press Cellular Signaling].

The other observed difference in activitydependent regulation between primary cells and the immortalized cell lines is the regulation of myogenin RNA. Myogenin is thought to be an important mediator of activity-dependent transcription. In primary muscle cells, we observe a decrease in myogenin RNA in response to electrical stimulation that is not as dramatically reflected in the RNA of the RMT cell lines. We do not currently know what mechanism is responsible for this difference, but given that myogenin protein levels are regulated similarly inprimary cells and RMT's it appears that in the post-transcriptional pathways mediating myogenin activity, as related to activity-dependent regulation, are likely to be intact in the cell lines.

The activity-dependent data we have presented demonstrates the fidelity with which the cell lines respond to the suppressive effects of muscle activity. Although we have no direct evidence that the cell lines are equally reliable in portraying the inductive signals of muscle stimulation, we assume that this will be the case based on the developmental similarities of the cell lines with primary muscle cells. It will be interesting to determine if proteins that are induced by activity in skeletal muscle, such as some of the contractile proteins [Cerny and Bandman, 1986; Torgan and Daniels, 2001], display a similar phenotype in the cell lines.

In addition to the applications described above, the cell lines appear to be readily transfectable either as myoblasts or myotubes. Consequently, they are amenable to reporter assays, as well as further genetic manipulation. Moreover, given their dual mode of growth regulation they may be less likely to display the tumorgenic characteristics that have been describe for other muscle cell lines when reintroduced in vivo [Iujvidin et al., 1990; Morgan et al., 2002].

\section{ACKNOWLEDGMENTS}

We thank Dr. S. Burden for the MuSK cDNA, Dr. K. Huppi for the p21 cDNA, Dr. E. Wang for the Rb cDNA, and Dr. M. Ferns for the agrin expression contructs (pCMV-cAg4,8 and pCMV$\mathrm{Ag} 12,4,8)$, and Dr. F. Gage for use of the NITTag construct. The monoclonal antibodies developed by W.E. Wright (F5D), D.A. Fischman (MF20), and A. Kawakami (Pax7) were obtained from the Developmental Studies Hybridoma Bank developed under the auspices of the NICHD and maintained by the University of Iowa, Department of Biological Sciences, Iowa City, IA 52242.

\section{REFERENCES}

Aaronson SA, Todaro GJ. 1968. SV40 T antigen induction and transformation in human fibroblast cell strains. Virology 36:254-261.

Adams L, Goldman D. 1998. Role for calcium from the sarcoplasmic reticulum in coupling muscle activity to nicotinic acetylcholine receptor gene expression in rat. J Neurobiol 35:245-257.

Adams L, Carlson BM, Henderson L, Goldman D. 1995. Adaptation of nicotinic acetylcholine receptor, myogenin, and MRF4 gene expression to long-term muscle denervation. J Cell Biol 131:1341-1349.

Bessereau JL, Stratford-Perricaudet LD, Piette J, LePoupon C, Changeux JP. 1994. In vivo and in vitro analysis of electrical activity-dependent expression of muscle acetylcholine receptor genes using adenovirus. Proc Natl Acad Sci USA 91:1304-1308.

Blau HM, Chiu CP, Webster C. 1983. Cytoplasmic activation of human nuclear genes in stable heterocaryons. Cell $32: 1171-1180$. 
Bowen DC, Park JS, Bodine S, Stark JL, Valenzuela DM, Stitt TN, Yancopoulos GD, Lindsay RM, Glass DJ, DiStefano PS. 1998. Localization and regulation of MuSK at the neuromuscular junction. Dev Biol 199: 309-319.

Brown M, McCormack M, Zinn KG, Farrell MP, Bikel I, Livingston DM. 1986. A recombinant murine retrovirus for simian virus 40 large $\mathrm{T}$ cDNA transforms mouse fibroblasts to anchorage-independent growth. J Virol 60: 290-293.

Buckingham M, Bajard L, Chang T, Daubas P, Hadchouel J, Meilhac S, Montarras D, Rocancourt D, Relaix F. 2003. The formation of skeletal muscle: From somite to limb. J Anat 202:59-68.

Buller AJ, Mommaerts WF, Seraydarian K. 1969. Enzymic properties of myosin in fast and slow twitch muscles of the cat following cross-innervations. J Physiol 205:581597.

Buonanno A, Apone L, Morasso MI, Beers R, Brenner HR, Eftimie R. 1992. The MyoD family of myogenic factors is regulated by electrical activity: Isolation and characterization of a mouse Myf-5 cDNA. Nucleic Acids Res 20:539-544.

Cerny LC, Bandman E. 1986. Contractile activity is required for the expression of neonatal myosin heavy chain in embryonic pectoral muscle cultures. J Cell Biol 103:2153-2161.

Chahine KG, Walke W, Goldman D. 1992. A 102 base pair sequence of the nicotinic acetylcholine receptor deltasubunit gene confers regulation by muscle electrical activity. Development 115:213-219.

Chahine KG, Baracchini E, Goldman D. 1993. Coupling muscle electrical activity to gene expression via a cAMPdependent second messeger system. J Biol Chem 268: 2893-2898

Duclert A, Piette J, Changeux JP. 1991. Influence of innervation on myogenic factors and acetylcholine receptor alpha-subunit mRNAs. Neuroreport 2:25-28.

Dutton EK, Simon AM, Burden SJ. 1993. Electrical activity-dependent regulation of the acetylcholine receptor $\delta$-subunit gene, $M y o D$ and myogenin in primary myotubes. Proc Natl Acad Sci USA 90:2040-2044.

Ferns MJ, Campanelli JT, Hoch W, Scheller RH, Hall Z. 1993. The ability of agrin to cluster AChRs depends on alternative slicing and on cell surface proteoglycans. Neuron 11:491-502.

Goldman D, Brenner HR, Heinemann S. 1988. Acetylcholine receptor $\alpha-, \beta-, \gamma-$, and $\delta$-subunit mRNA levels are regulated by muscle activity. Neuron 1:329-333.

Goldman D, Carlson BM, Staple J. 1991. Induction of adulttype nicotinic acetylcholine receptor gene expression in noninnvervated regenerating muscle. Neuron 7:649658

Gossen M, Bujard H. 1992. Tight control of gene expression in mammalian cells by tetracycline-responsive promoters. Proc Natl Acad Sci USA 89:5547-5551.

Gundersen K, Rabben I, Klocke BJ, Merlie JP. 1995. Overexpression of myogenin in muscles of transgenic mice: Interaction with Id-1, negative crossregulation of myogenic factors, and induction of extrasynaptic acetylcholine receptor expression. Mol Cell Biol 15:71277134.

Henderson IC, Livingston DM. 1974. Partial purification and characterization of the SV40 T antigen. Cell 3:65-70.
Hicok KC, Thomas T, Gori F, Rickard DJ, Spelsberg TC, Rigs BL. 1998. Development and characterization of conditionally immortalized osteoblast precursor cell lines from human bone marrow stroma. J Bone Miner Res 13:205-217.

Hoshimaru M, Ray J, Sah DW, Gage FH. 1996. Differentiation of the immortalized adult neuronal progenitor cell line HC2S2 into neurons by regulatable suppression of the v-myc oncogene. Proc Natl Sci USA 93:15181523.

Huang CF, Tong J, Schmidt J. 1992. Protein kinase C couples membrane excitation to acetylcholine receptor gene inactivation in chick skeletal muscle. Neuron 9: $671-678$

Iujvidin S, Fuchs O, Nudel U, Yaffe D. 1990. SV40 immortalizes myogenic cells: DNA synthesis and mitosis in differentiating myotubes. Differentiation 43:192-203.

Jat PS, Sharp PA. 1989. Cell lines established by a temperature-sensitive simian virus 40 large-T-antigen gene are growth restricted at the nonpermissive temperature. Mol Cell Biol 9:1672-1681.

Kimes BW, Brandt BL. 1976. Properties of a clonal muscle cell line from rat heart. Exp Cell Res 98:367-381.

Klarsfeld A, Laufer R, Fontaine B, Devillers-Thiéry A, Dubreuil C, Changeux JP. 1989. Regulation of muscle AchR subunit gene expression by electrical activity: Involvement of protien kinase $\mathrm{C}$ and $\mathrm{Ca} 2+$. Neuron 2 : 1229-1236.

Linkhart TA, Clegg CH, Hauschka SD. 1980. Control of mouse myoblast commitment to terminal differentiation by mitogens. J Supramol Struct 14:483-498.

Macpherson P, Kostrominova T, Tang H, Goldman D. 2002. Protein kinase $\mathrm{C}$ and calcium/calmodulin-activated protein kinase II (CaMK II) suppress nicotine acetycholine receptor gene expression in mammalian muscle. A specific role for CaMK II in activity dependant gene expression. J Biol Chem 277:15638-15646.

Mendelzon D, Changeux JP, Nghiem HO. 1994. Phosphorylation of myogenin in chick myotubes: Regulation by electrical activity and by protein kinase C. Implications for acetylcholine receptor gene expression. Biochemistry 33:2568-2575.

Morgan JE, Gross JG, Pagel CN, Beauchamp JR, Fassati A, Thrasher AJ, Di Santo JP, Fisher IB, Shiwen X, Abraham DJ, Partridge TA. 2002. Myogenic cell proliferation and generation of a reversible tumorigenic phenotype are triggered by preirradiation of the recipient site. J Cell Biol 157:693-702.

Mulle C, Benoit P, Pinset C, Roa M, Changeux JP. 1988. Calcitonin gene-related peptide enhances the rate of desensitization of the nicotinic acetylcholine receptor in cultured mouse muscle cells. Proc Natl Acad Sci USA 85:5728-5732.

Neville CM, Schmidt M, Schmidt J. 1992. Response of myogenic determination factors to cessation and resumption of electrical activity in skeletal muscle: A possible role for myogenin in denervation supersensitivity. Cell Mol Neurobiol 12:511-527.

Pette D, Vrbova G. 1992. Adaptation of mammalian skeletal muscle fibers to chronic electrical stimulation. Rev Physiol Biochem Pharmacol 120:115-202.

Rando TA, Blau HM. 1994. Primary mouse myoblast purification, characterization, and transplantation for cell-mediated gene therapy. J Cell Biol 125:1275-1287. 
Robbins JR, Thomas B, Tan L, Choy B, Arbiser JL, Berenbaum F, Goldring MB. 2000. Immortalized human adult articular chondrocytes maintain cartilage-specific phenotype and responses to interleukin-1beta. Arthritis Rheum 43:2189-2201.

Seale P, Sabourin LA, Girgis-Gabardo A, Mansouri A, Gruss P, Rudnicki MA. 2000. Pax7 is required for the specification of myogenic satellite cells. Cell 102:777786.

Seale P, Asakura A, Rudnicki MA. 2001. The potential of muscle stem cells. Dev Cell 1:333-342.

Simon LV, Beauchamp JR, O'Hare M, Olsen I. 1996. Establishment of long-term myogenic cultures from patients with Duchenne muscular dystrophy by retroviral transduction of a temperature-sensitive SV40 large T antigen. Exp Cell Res 224:264-271.

Suhr ST, Senut MC, Whitelegge JP, Faull KF, Cuizon DB, Gage FH. 2001. Indentities of sequestered proteins in aggregates from cells with induced polyglutamine expression. J Cell Biol 153:283-294.

Tang H, Sun Z, Goldman D. 2001. CaM kinase IIdependent suppression of nicotinic acetylcholine receptor $\delta$-subunit promoter activity. J Biol Chem 276:2605726065.

Tenen DG, Martin RG, Anderson J, Livingston DM. 1977. Biological and biochemical studies of cells transformed by simian temperatures-sensitive gene A mutants and A mutant revertants. J Virol 22:210-218.

Torgan CE, Daniels MP. 2001. Regulation of myosin heavy chain expression during rat skeletal muscle development in vitro. Mol Biol Cell 12:1499-1508.

Valenzuela DM, Stitt TN, DiStefano PS, Rojas E, Mattsson K, Compton DL, Nunez L, Park JS, Stark JL, Geis DR, Thomas S, LeBeau MM, Fernald AA, Copeland NG, Jenkins NA, Burden SJ, Glass DJ, Yancopoulos GD. 1995. Receptor tyrosine kinase specific for the skeletal muscle lineage: Expression in embryonic muscle, at the neuromuscular junction and after injury. Neuron 15 : 573-584.

Whalen RG, Sell SM, Butler-Browne GS, Schwartz K, Bouveret P, Pinset-Harstrom I. 1981. Three myosinheavy chain isozymes appear sequentially in rat muscle development. Nature 292:805-809.

Witzemann V, Brenner HR, Sakmann B. 1991. Neural factors regulate AChR subunit mRNAs at rat neuromuscular synapses. J Cell Biol 114:125-141.

Yaffe D. 1968. Retention of differentiation potentialities during prolonged cultivaltion of myogenic cells. Proc Natl Acad Sci USA 61:477-483.

Yang J, Seelig M, Rayner S, Bredesen DE. 1992. Increasing the proliferative capacity of muscular dystrophy myoblasts. Muscle Nerve 15:941-948. 